\title{
Simulation of a Process Plant for the Production of Propylene
}

\author{
Amachree Blessing, Kenneth K. Dagde, Jackson Akpa \\ Department of Chemical/Petrochemical Engineering, Rivers State University, Nkpolu-Oroworukwu Port Harcourt, Nigeria \\ Email: Blessingamachree001@gmail.com
}

How to cite this paper: Blessing, A., Dagde, K.K. and Akpa, J. (2020) Simulation of a Process Plant for the Production of Propylene. Advances in Chemical Engineering and Science, 10, 322-331. https://doi.org/10.4236/aces.2020.104020

Received: July 20, 2020

Accepted: September 15, 2020

Published: September 18, 2020

Copyright $\odot 2020$ by author(s) and Scientific Research Publishing Inc. This work is licensed under the Creative Commons Attribution International License (CC BY 4.0).

http://creativecommons.org/licenses/by/4.0/

(c) (i) Open Access

\begin{abstract}
The simulation of a process plant for the production of propylene has been considered in this work. The reactor used for this research was a Continuous Stirred Tank Reactor (CSTR) which was deliberately picked because of the advantage of good temperature and reaction control. Other equipment includes a compressor, conversion reactor, cooler and splitter. Sizing was done for all equipment but detailed design was carried out for the CSTR since it's the heart of the process plant. The principle of conservation of mass was applied for the development of basic design performance equations for the volume, the height, space time, space velocity and heat generated per unit volume at $90 \%$ conversion of propane to propylene. Aspen Hysys which is known for its reliability in chemical engineering process design was used to simulate the process plant and was used for all calculations and sizing of process equipment. The values of the functional and dimensional parameters which are required for the sizing of the reactor were obtained after the simulation with the following results: volume of reactor $37 \mathrm{~m}^{3}$, height of reactor $7.4 \mathrm{~m}$, space time $0.028 \mathrm{hr}$, space velocity $59 \mathrm{hr}^{-1}$ and heat load $78 \mathrm{kj} / \mathrm{m}^{3}$.
\end{abstract}

\section{Keywords}

Simulation, Aspen Hysys, CSTR, Compressor, Conversion

\section{Introduction}

The utilization of natural gas for the production of useful chemicals is very important in the process and manufacturing industries. Owing the depletion of crude oil reserves coupled with the environmental pollution problems of crude oil processing, there is a pertinent need to utilize the vast natural gas reserves in Nigeria. Over the years, the utilization of natural gas has been majorly for the production of energy but with recent development in technology and advance- 
ment in chemical engineering processes, natural gas can be converted into useful chemicals that can also serve as starting raw materials for the production of a wide range of products which cuts across all manufacturing and producing industries. Bulk of the importance is seen in the plastic industry where the natural gas is converted to polymer grade gasoline which is used for the production of polymeric plastics of different grades and forms with useful applications in homes, offices and organizations. The importance of natural gas as a raw material for the production of useful chemicals has made many researchers to carry out several researches on the utilization of natural gas.

Due to the rise in the demand for renewable energy alternative for the production of goods and services [1], in his work considered how propylene and methanol could be produced using Aspen hysys for the simulation of the process. Two methods were used for the production process, which include: direct and indirect gasification. One of the products obtained which is tar was produced through the process of catalytic steam reforming. After the purification of the products has been done the syngas reacted further to produce methanol which was finally converted to olefins such as ethylene, propylene and butene. Economic consideration to ascertain which method will be more profitable was also investigated.

Worked on the development of a model that was able to estimate the level of impurities found in the upper and lower portions as well as the needed refrigerant [2]. NPSOL was the optimization method used to find the optimal points/values in developed plant model. The result of the optimization showed that the separation of the process and the refrigerants limit the maximum waste coming from the furnace. Also by manipulating the flowrate of steam to hydrocarbon ratio, the profit rise is about $6 \%$ above the original values. The plant model developed consist of the following parts: thermal cracking section, separation section and integrated refrigeration section.

Worked on the manufacture of ethylene and propylene from natural gas through the catalytic pyrolysis of methyl chloride produced by methane catalytic chlorination [3]. The catalyst used for the process was silicoaliminuimphosphate and the percent selectivities for ethylene and propylene were $45 \%$ and $35 \%$ respectively while the conversion of the methyl chloride was $70 \%$. The kinetics of the process was also studied with different reactor type such as fluidized catalytic bed, tubular and adiabatic reactors. The operating temperature was found within the range of $400^{\circ} \mathrm{C}$ to $420^{\circ} \mathrm{C}$.

Over the years the need for the production of propene has been on the rise especially in European countries between the year 2000 to 2008 [4]. This rise in demand has considerably shifted to East Asia specifically Singapore and China. Worldwide production is now almost 50\% when compared to the production rate of ethylene and about 33\% is now been produced and used as a by product of petroleum. Also about $7 \%$ from the dehydrogenation of propane while the remaining is from catalytic cracking of vacuum distillation unit. 
There has been a drop in the production rate of propylene drastically globally as indicated in Figure 1, showing the different countries and their percent production rate [5]. It can be observed that USA has the highest production rate followed by China with $19 \%$ between the periods of 2008 to 2010. Part of the reasons for the decrease in the production rate can be attributed to the economic recession that occurred within the given periods as well as the global demand for the product. The consumption rate of propylene has been predicted to rise above the Gross domestic product over the next five years with an average production rate of $5 \%$ per year.

\section{Materials and Methods}

\subsection{Materials}

The Materials used in this work are Data from Chemical Engineering Handbooks which includes:

1) Detailed process flow diagram

2) Inlet feed operating conditions

3) Comprehensive feed compositions

4) Utilities

5) Aspen Hysys Version 8.8 software

6) Matlab software

7) Chemical Engineering related Handbooks, etc.

\subsection{Methods}

1) Material and Energy balance

2) Plant Simulation

\subsubsection{Material Balance Equation for the Reactor}

Applying the conservation principle, the general form of material balance equation for any process is given as:

Rate of accumulation of component $i$ wihtin the reactor

$=$ Rate of input of component $i-$ Rate of output of component $i$

- Rate of deplection of species $i$ by chemical reaction

\subsubsection{Volume of Reactor}

The volume of reactor is a very important dimensional parameter to be determine in the design of any process as it has a direct effect on the overall performance of the system. The volume is a function of the diameter of the reactor and increases as the diameter increases. For a CSTR, the volume can be obtained from Equation (3.13) as:

$$
\begin{aligned}
& V=\frac{C_{i o} V_{o} X_{A}}{-r_{A}} \\
& V=\frac{C_{i o} V_{o} X_{A}}{-r_{A}}
\end{aligned}
$$




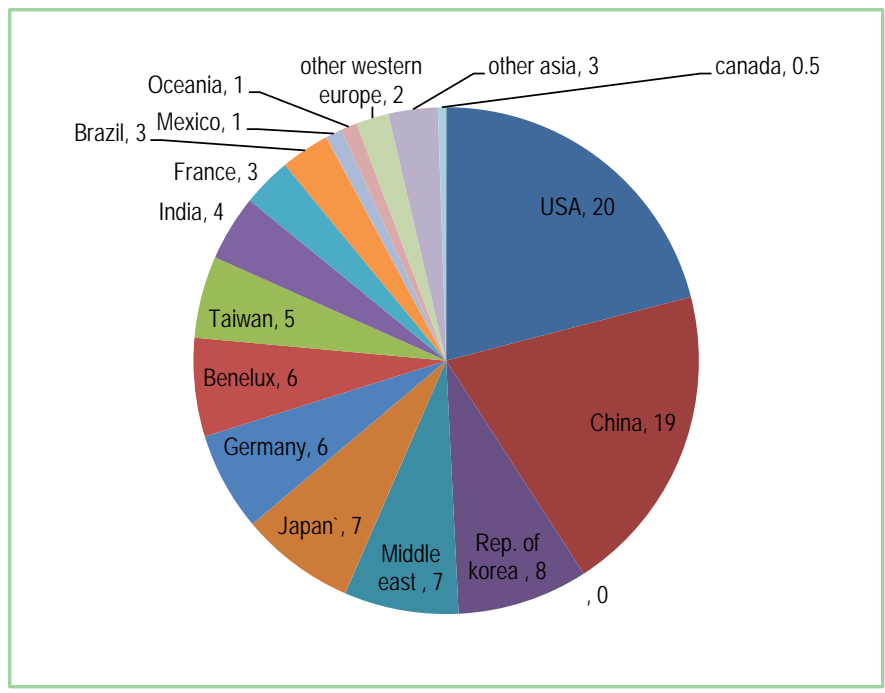

Figure 1. World consumption of propylene (Dusselier et al., 2013).

\subsubsection{Height of Reactor}

The height of reactor is also a very important dimensional parameter to be determined in the design of any process. It has a direct relationship with the volume of the reactor and tends to have same effect on the process as the volume. The height of the reactor also affects the cost of the reactor, hence the need to calculate the height of the system based on the basis of the design under consideration to avoid wastage and unnecessary costs. For the CSTR, assuming a cylindrical shape:

Recall: Volume of cylinder is given as:

$$
V=\frac{\pi D^{2} H}{4}
$$

Making height $(H)$ the subject of formula

$$
H=\frac{4 V}{\pi D^{2}}
$$

\subsubsection{Space Time}

The space time is defined as the reaction time required to process one reactor volume of feed measured at specified condition. It is otherwise known as holding or mean residence time.

Mathematically stated:

$$
\tau=\frac{V}{V_{o}}
$$

\subsubsection{Space Velocity}

Space velocity is defined as the numbers of reactor volumes of feed at specified conditions which can be treated per unit time and is designated as $S_{v}$. It is the reciprocal of the space time.

Mathematically $S_{v}$ is expressed as:

$$
S_{v}=\frac{V_{o}}{V}
$$




\subsubsection{Heat Load}

The heat load is a function of molar flow feed rate, the degree of conversion and heat of reaction and is expressed as;

$$
Q=\Delta H_{R}^{o} F_{i o} X_{i}
$$

\subsubsection{Energy Balance}

The first law of thermodynamics requires that the rate of heat transfer to the cold body is equal to the rate of heat transfer from a hot body, on assumption that there is no heat loss to the surrounding medium, and any heat transfer occurs between the two fluid only.

$$
Q_{h c}=Q_{c}=Q_{h}
$$

where:

$Q_{\mathrm{hc}}=$ total flow rate

$Q_{c}$ and $Q_{h}=$ Cold and Hot stream flow rate respectively.

Similarly, the energy balance is written as:

$$
Q=m_{c} C_{P C}\left(\Delta T_{c}\right)=m_{h} C_{P h}\left(\Delta T_{h}\right)
$$

1) Plant Simulation

The plant model was built into Aspen Hysys process model which is shown in Figure 2.

\section{Results and Discursion}

\subsection{Results}

To describe the operation of the dehydrogenation plant for propylene production, Aspen Hysys was employed to design and simulate the process plant. The mathematical models of the reactor dimensional and functional parameters which is the major concern in this research as developed by applying the principles of conservation of mass and energy are all embedded in Aspen Hysys making it easier and more validated approach in calculating the reactor's functional and dimensional parameters for the process. The results obtained from the Aspen Hysys simulation will be exported to MATLAB (2015b) where plotting of the variations of the functional and dimensional parameters will be done (see Tables 1-3).

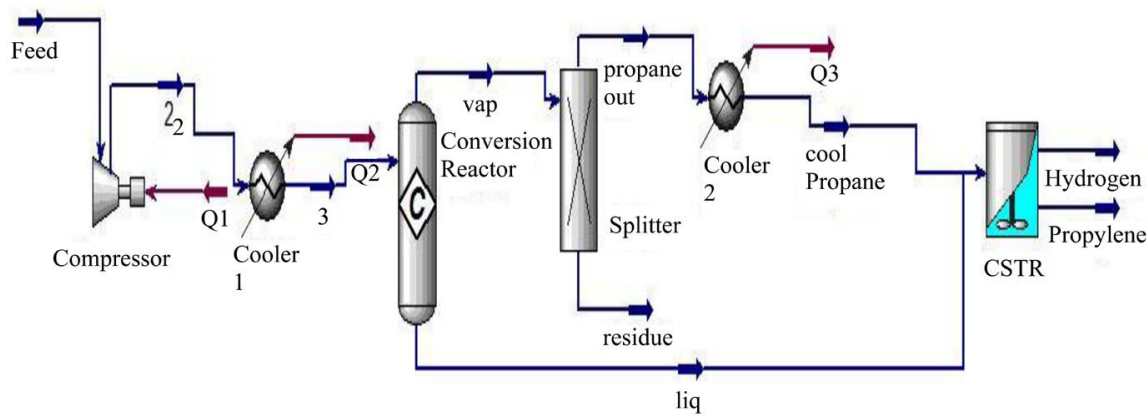

Figure 2. Aspen hysys simulation of the dehydrogenation plant for propylene production. 
Table 1. Parameters for reactor sizing at 90\% fractional conversion.

\begin{tabular}{cc}
\hline Parameter & Result \\
\hline Volume & $37 \mathrm{~m}^{3}$ \\
Height & $7.4 \mathrm{~m}$ \\
Space Time & $0.028 \mathrm{hr}$ \\
Space Velocity & $59 \mathrm{hr}^{-1}$ \\
Heat generated per unit volume & $78 \mathrm{KJ} / \mathrm{m}^{3}$ \\
\hline
\end{tabular}

Table 2. Parameters for compressor sizing.

\begin{tabular}{cc}
\hline Parameter & Result \\
\hline Adiabatic Efficiency & $75 \%$ \\
Polytropic Efficiency & $76.646 \%$ \\
Duty & $694.983 \mathrm{~kW}$ \\
Pressure Drop & $484 \mathrm{KPa}$ \\
Pressure Ratio & 3.42 \\
\hline
\end{tabular}

Table 3. Parameters for conversion column sizing.

\begin{tabular}{cc}
\hline Parameter & Result \\
\hline Diameter & $0.76 \mathrm{~m}$ \\
Length & $4.191 \mathrm{~m}$ \\
L/D Ratio & 5.0 \\
Maximum Allowable Vapour Velocity & $0.6376 \mathrm{~m} / \mathrm{h}$ \\
\hline
\end{tabular}

\subsection{Discussion}

The graphical representations showing the variations of the dimensional and functional parameters of the reactor with fractional conversion are presented and discussed in this section.

\subsubsection{Variation of Volume of the Reactor with Fractional Conversion}

The volume of the reactor which is a very important functional parameter depicts the total area and height occupied by the reactor. It gives us the information of the capacity of the reactor.

Figure 3, shows that as the volume of the reactor increases, the conversion of propane to propene through the process of dehydrogenation also increase. Hence, it could be concluded from the plot that the conversion is directly proportional to the volume of reactor. This increment was due to the fact that the reacting species had large surface area to reacts, this large surface area for reaction led to an increase in the yield of products. Thus, for a reasonable feed conversion and high reactor production of propylene, a large reactor size should be used.

\subsubsection{Variation of Height of the Reactor with Fractional Conversion}

The height of the reactor is another very important dimensional parameter for the design of a reactor. The height gives us an idea on how long the reactor will 
be based on the kinetics of the reaction process taking place in the reactor.

Figure 4 shows that as the height of the reactor increases, the conversion from propane to propene also increase. Hence, it could be concluded that the conversion is directly proportional to the height of the reactor. This is as a result of an increased in contact time caused by an increase in the height of the reactor.

The increment was due to the fact that in reactor, the rate of formation of product increases along the height of the reactor. This increment in the rate of formation of product along the height of the reactor leads to a higher conversion rate which resulted to an increase in the yield of product.

\subsubsection{Variation of Rate of Reaction with Reactor Height}

Figure 5 show the variation of the rate of reaction along the reactor height. From the plot, it is seen that the rate of reaction decreases along the reactor height. The decrease in the rate of reaction was as a result of decrease in the concentrations of the reacting species as the reaction proceeds along the reactor.

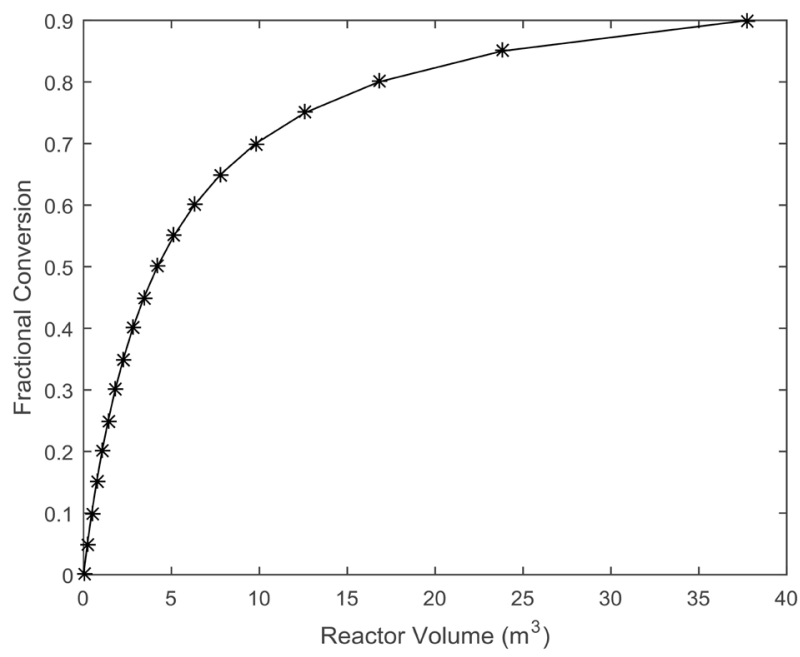

Figure 3. Volume variations with fractional conversion.

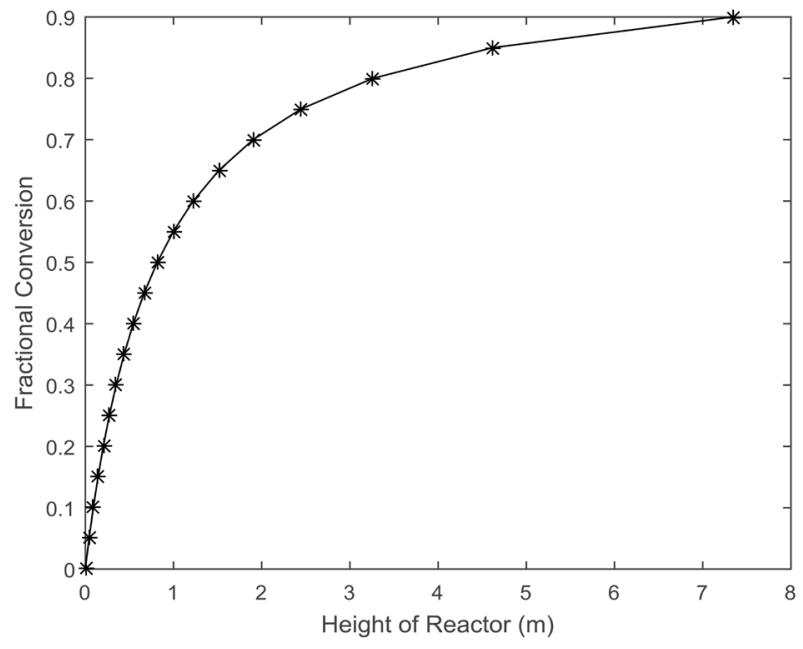

Figure 4. Reactor height variation with fractional conversion. 


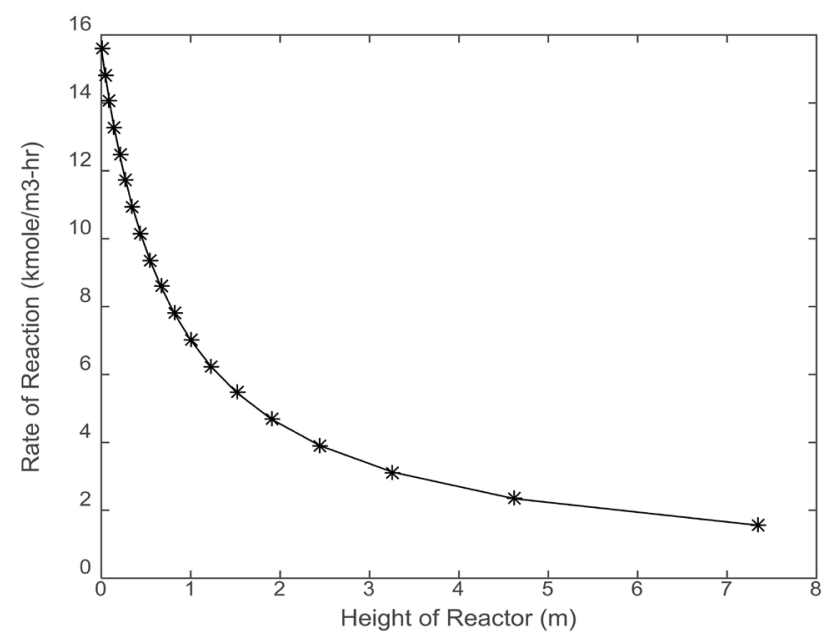

Figure 5. Rate of reaction variation along reactor height.

\subsubsection{Variation of Space Time with Fractional Conversion}

Space time is also an important functional parameter in the design of continuous reactors. The space time gives the information of the amount of time required to process a given volume of feed at inlet conditions.

Figure 6, shows that as the space time of the reactor increases, the fractional conversion of the propane to propene also increase. Hence, it could be concluded from the plot that the conversion is directly proportional to the total amount of time spent by the reacting species in the reactor. The more time the reacting species spend in the reactor, the more the yield of products.

\subsubsection{Variation of Space Velocity with Fraction Conversion}

The space velocity is also another important functional parameter in the design of reactors. The value of the space velocity gives us the information of the number of reactor volume of feed process per time.

Figure 7 shows that the fractional conversion decreases with an increase in the space velocity. Hence, the conversion is inversely proportional to the space velocities of the reactor. That means that, with an increment in the space velocity of the species, there will be a corresponding decrease in the conversion of the reacting species.

\subsubsection{Heat Load}

The heat load is the amount of heat required in maintaining the temperature of the reaction process. It could be seen that the heat load decreases along the reactor height, the decrease could emanate from the endothermic nature of the dehydrogenation reaction (see Figure 8).

\section{Conclusion}

The demand of today for polymers for the manufacture of diverse home and industrials products provoked this research which is aimed at designing a dehydrogenation process plant for the production of propylene from propane. 


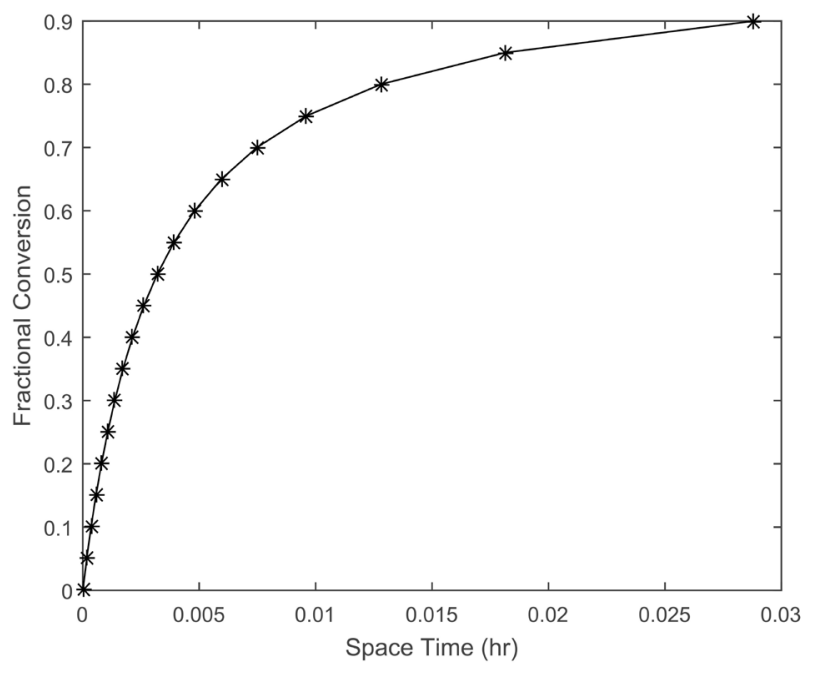

Figure 6. Space time variations with fractional conversion.

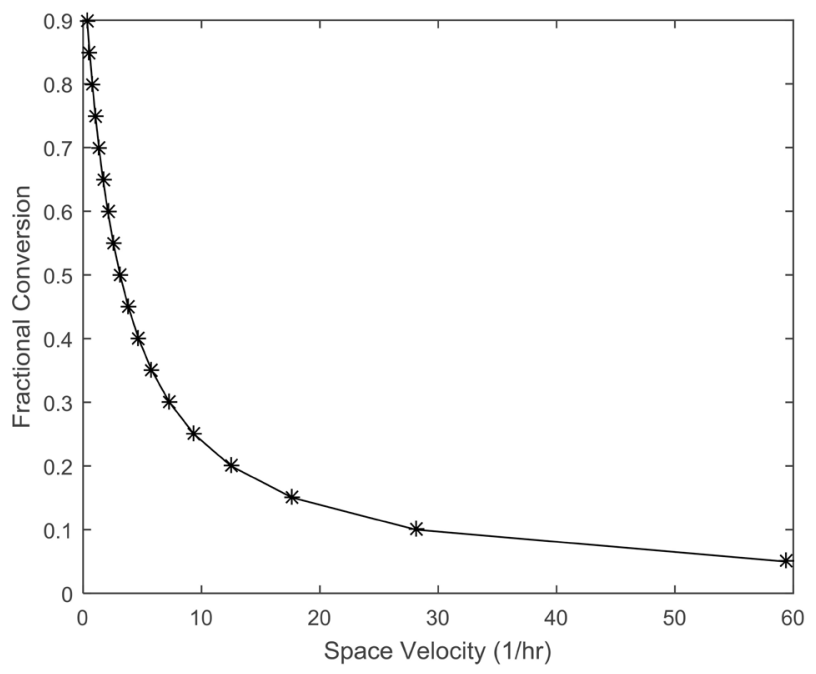

Figure 7. Space velocity variations for the reactor.

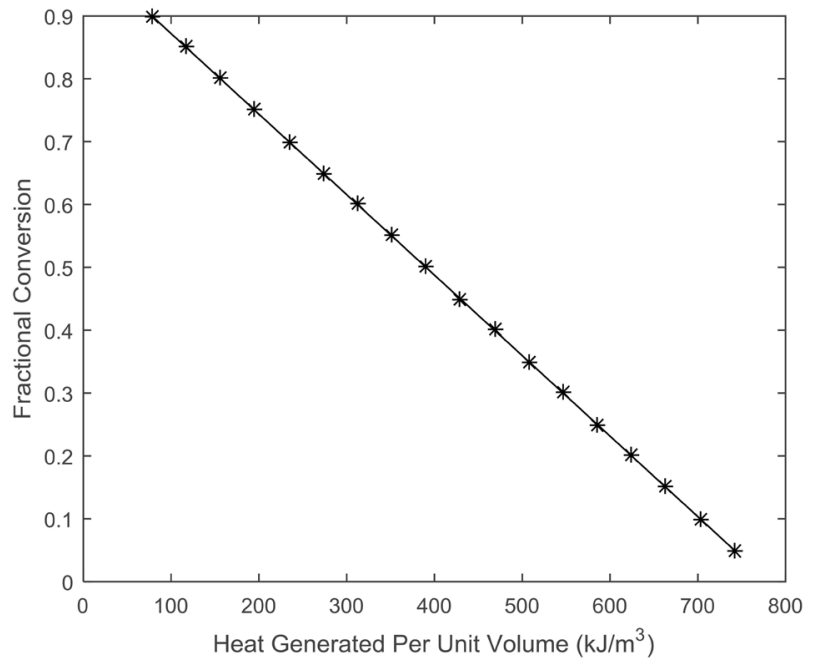

Figure 8. Heat load variation along reactor height. 
Despite the intended use of a computer software to carry out the design of the process plant, mathematical models representing the design performance equations were developed from the principle of conservation of mass to show a firm understanding of the principles of chemical engineering as applied by the software. The design considered the major equipment and a continuous stirred tank reactor for the dehydrogenation process. The kinetics of the process was modeled with Aspen Hysys in the form of a conversion reaction which was a good representative of the actual dehydrogenation kinetics. Peng Robinson fluid package was used as the solver for the process design equations. The results from the computer aided design depict reactor functional and dimensional parameters which are in reasonable agreement with recommended dimensions and functional parameters from literatures. The volume of the reactors was $37 \mathrm{~m}^{3}$ at $90 \%$ conversion of the feed and the height was $7.4 \mathrm{~m}$. The following reactor functional parameters were evaluated; Space time, Space velocity, and Heat load. The dependency profile of the reactor design parameters at varying fractional conversion was shown and discussed.

\section{Conflicts of Interest}

The authors declare no conflicts of interest regarding the publication of this paper.

\section{References}

[1] Bernardo, R.L. (2016) Process Design and Simulation of Propylene and Methanol Production through Direct and Indirect Biomass Gasification.

https://etd.auburn.edu

[2] Inazu, K., Koyama, T., Miyaji, A. and Baba, T. (2008) Propene Production from Ethene and Methane Using Silver- and Proton-Exchanged Zeolite Catalysts, Elsevier, 101, 142-147.

[3] He, J., Xu, T., Wang, Z., Zhang, Q., Deng, W. and Wang, Y. (2012) Transformation of Methane to Propylene: A Two-Step Reaction Route Catalyzed by Modified $\mathrm{CeO}_{2}$ Nanocrystals and Zeolites. Petroleum Institute, 51, 2438-2442.

https://doi.org/10.1002/anie.201104071

[4] Treger, Y.A., Rozanov, V.N., Sokolova S.V. and Murashova, O.P. (2012) Production of Ethylene and Propylene from Natural Gas via the Intermediate Synthesis of Methyl Chloride and Its Subsequent Catalytic Pyrolysis. Catalysis in Industry, 4, 231-235. https://doi.org/10.1134/S2070050412040186

[5] Dusselier, M., Wouwe, P.V., Dewaele, A., et al. (2013). Lactic acid as a Platform Chemical in the Biobased Economy: the Role of Chemocatalysis. Energy \& Environmental Science, 6, 1415-1442. https://doi.org/10.1039/c3ee00069a 